\section{Primary excision of cutaneous melanoma}

It seemed almost inevitable that there would be a secondary care backlash towards GPs being 'let loose' with a scalpel ('Primary excision of cutaneous melanoma').1-4

Any GP practising regular minor surgery sessions over many years will surely unwittingly excise the very occasional malignant skin lesion. I have no doubt that dermatologists occasionally mistakenly excise a benign one!

Are we not in danger of over reacting here? Perhaps GPs should not treat patients with a heart condition. Now that really is serious isn't it?

\section{Peter Perkins,}

Southbourne Surgery, 17 Beaufort Road, Bournemouth, BH6 5BF.

E-mail: peter.perkinsladorset.nhs.uk

\section{REFERENCES}

1. Murchie P, Sinclair E, Lee AJ. Primary excision of cutaneous melanoma: does the location of excision matter? Br J Gen Pract 2011; 61(583): 131-134.

2. Hayes S, Keohane S. Primary excision of cutaneous melanoma. Br J Gen Pract 2011; 61(585): 290-291.

3. Muller F, Meredith F, Ormerod A. Primary excision of cutaneous melanoma. Br J Gen Pract 2011; 61(585): 291-292.

4. Wake J. Primary excision of cutaneous melanoma. Br J Gen Pract 2011; 61(585): 292.

DOI: 10.3399/bjgp11X572580

\section{Working with non-medical prescribers}

Courtenay et al highlight the expansion of non-medical prescribing in the UK and argue that it offers 'a strategic innovative solution to address capacity, quality, efficiency, and effectiveness'.' They believe that doctors' anxieties about non-medical prescribing should be allayed by the available evidence, although they are concerned about the lack of awareness and understanding by doctors about this literature'. ${ }^{1}$

However, some of the categorical statements made in the editorial are supported by references that suggest, rather than clearly demonstrate, the benefits of non-medical prescribing.

For example, one reference that is used (solely) to support six different statements relating to such matters as GP' confidence in nurse prescribing, the 'freeing up' of GPs' time by nurse prescribing, and non-medical prescribers staying within their area of competence, is a study involving interviews with just five GPs and seven hospital doctors working with nurse prescribers in dermatology. ${ }^{2}$ Indeed, the authors of this study noted that 'generalization of the findings is limited by the small sample size'?

Furthermore, the supporting reference for the assertion that nurse prescribing is safe' is an Irish report ${ }^{3}$ that looked at the educational preparation for nurse and midwife prescribing, and the perceptions of patients and healthcare professionals. An audit was also conducted which found that the 'vast majority' of prescriptions and consultations were appropriate and safe; however, this was based on a review of 25 nurse and midwife prescribers.

I have worked closely with several hardworking and professional nurseprescribers and understand the potential benefits to patients and GPs of these extended roles. However, it appears that claims about the benefits and safety of non-medical prescribing, based on some of the evidence referenced in the editorial, should be treated as probable rather than proven.

Bruno Rushforth,

GP and Clinical Research Fellow, Academic Unit of Primary Care, Leeds. E-mail: b.j.rushforthaleeds.ac.uk

Please see the BJGP Discussion Forum for the authors' response:

http://www.rcgp.org.uk/bjgp-discuss

\section{REFERENCES}

1. Courtenay M, Gerada C, Haywood J. Working with non-medical prescribers. Br J Gen Pract 2011; 61(583): 85-86.

2. Stenner K, Carey N, Courtenay M. Nurse prescribing in dermatology: doctors' and non-prescribing nurses' views. J Adv Nurs 2009; 65(4): 851-859.
3. Drennan J, Naughton C, Allen D, et al. National independent evaluation of the nurse and midwife prescribing initiative. Dublin: University College Dublin, 2009.

DOI: 10.3399/bjgp11X572382

\section{How to protect general practice from child protection}

Mike Fitzpatrick is clearly struggling with child protection and probably finds resonance with other GPs who feel the same. ${ }^{1}$ Careless words cost lives, and I believe Mike and the editors of the Journal should remember this.

As a medical student I was drawn to general practice by the The Journal of the Royal College of General Practitioners and the RCGP focus on the physical, psychological, and social components of the consultation. I was very fortunate to have trained in practice with the late Dr Eric Gambrill, where this spirit of working together with other professionals in challenging cases was promoted with enthusiasm. It is sad to see the Journal potentially helping to erect barriers to safeguarding children. As a GP and a Named Doctor for Safeguarding Children, may I suggest the following:

- Don't give up on safeguarding children. Read the PreVAil report showing the continuum of abuse and neglect in infancy to conditions in later life, including academic failure, substance misuse, mental health disorder, maltreatment of one's own offspring, and chronic disease including heart disease and cancer. ${ }^{2}$

- Read the article 'Beyond the specific child' that highlights the fact that child protection cases in general practice so often present through parental issues and concerns, and suggests a refocus. ${ }^{3}$

- Continue to voice concerns about excessive child safeguarding guidance, (strident or not), and at the same time call for better resources for the complex tasks in primary care. Bearing in mind the PreVAil report, this may be more worth while than ticking boxes for QoF points. 